\title{
ISHRS Legal Update: Delegation of Surgery in Hair Transplantation
}

The ISHRS shares, from time to time, legal developments on issues potentially affecting members. One such issue is the permissibility of delegating portions of hair restoration procedures to unlicensed personnel. In the United States, a physician's authority to delegate to unlicensed personnel varies from state to state, and depends on each state's regulatory scheme.

Many states prohibit the delegation of surgery or medical tasks to unlicensed personnel.

The Florida Board of Medicine issued a Declaratory Statement in June 2016 that states that, "surgical excisions and incisions related to the transplantation of skin grafts goes well beyond the assisting of physicians." The Florida Board of Medicine further explained Section 458.3485, Florida Statutes, did not authorize the petitioning physician:

to delegate the task of harvesting follicular units consisting of the excision of skin, subcutaneous tissue and hair follicles by use of a scalpel, micro-punch, motorized surgical extraction device or similar surgical instrument or device and incising the scalp for transplanting such grafts, to a medical assistant, or any other person who is not licensed as a health care practitioner and appropriately trained or otherwise experienced in the performance of such surgical procedures, in an office setting.

The Florida Board of Medicine's Declaratory Statement is consistent with Resolution 16-130 adopted by the Florida Medical Association ("FMA") in 2016. In particular, the resolution provided:

RESOLVED, [t]hat the Florida Medical Association oppose the use of unlicensed personnel and/or medical assistants to perform critical-to-quality steps of hair restoration surgery, such as redistribution planning, donor harvesting of follicular units via FUE or strip methods, and creation of recipient sites; and be it further

RESOLVED, [t]hat the FMA oppose the use of unlicensed personnel and/or medical assistants to perform the diagnosis or treatment of hair loss conditions; and be it further

RESOLVED, [t]hat the FMA support legislative efforts to prohibit the use of unlicensed personnel and/or medical assistants to perform hair restoration evaluation, diagnosis, and/ or critical-to-quality steps of hair restoration surgery, such as diagnosis of hair loss etiology, hair re-distribution, planning, donor harvesting of follicular units via FUE or strip methods, and creation of recipient site.

An earlier decision by the Virginia Board of Medicine is also consistent with the Florida Board of Medicine's Declaratory Statement and the Florida Medical Association's recent resolution. In 2011, the Virginia Board of Medicine instituted disciplinary proceedings against a physician who permitted unlicensed individuals to regularly incise the scalp and insert hair grafts without direct supervision, which the Virginia Board of Medicine concluded in December 2011, violated 18 VAC 85-20-29.A(1), a regulation that prohibits knowingly allowing subordinates to provide patient care outside of the subordinate's scope of practice or area of responsibility.

The prohibition on the delegation expressed by the Florida Board of Medicine and the Virginia Board of Medicine are consistent with the ISHRS's position on delegation announced in the ISHRS Position Statement on Qualifications for Scalp Surgery, available at http://www.ishrs.org/content/ qualifications-scalp-surgery. These procedures should only be performed by a properly trained and licensed physician, or in countries where allowed, a licensed allied health professional within the scope of his or her license.

In addition to the foregoing examples from the United States, there are also recent international examples of charges being leveled against non-doctors performing hair restoration surgery. In September 2016, the Istanbul Attorney General's Office charged two individuals with treating patients without a diploma following a police raid that allegedly revealed them performing hair transplant surgeries at a clinic without a doctor being present. As of this writing, the case against these two individuals is pending, and the Attorney General's Office has requested prison sentences of 2-5 years.

The foregoing examples reinforce the importance of physicians, allied health professionals, and unlicensed persons involved in hair restoration to understand the legal restrictions on delegation in the jurisdictions in which they practice. Physicians, allied health professionals, and unlicensed persons involved in hair restoration surgery should carefully consider a number of factors in deciding whether delegation of a hair restoration surgery task is legal, ethical, consistent with the standard of care, and in the patient's best interests, including, whether:

(i) The delegation is legally permissible, consistent with the applicable standard of care, and consistent with the codes of ethics to which the physician or allied health professional is bound;

(ii) The unlicensed personnel has adequate education, training, and experience to perform the delegated tasks;

(iii) The level of supervision a physician must provide to the individual to whom the task is delegated (e.g., direct, in the same facility, available by phone, none) is being met;

(iv) Malpractice insurance covers the physician and unlicensed personnel;

(v) The patient provides informed consent for the procedure, including the delegated portion of the hair transplant surgery; and

(vi) Delegation of a portion of the hair transplant surgery is in the patient's best interest.

In summary, when deciding whether the delegation of medical tasks associated with hair restoration surgery is legal, ethical, and in the patient's best interests the physician and other individuals involved need to research and consider a number of factors. Relying on what others do or the assurances of a sales representative puts all those involved, including the patient, at risk. Accordingly, the ISHRS encourages physicians, allied health professionals, and unlicensed persons involved in hair restoration surgery to research and understand the legal restrictions on delegation in the jurisdictions in which they practice.

The International Society of Hair Restoration Surgery ("ISHRS") is a nonprofit corporation, exempt from federal income tax pursuant to Internal Revenue Code Section 501(c) (3), whose purpose includes educating physicians and their assistants regarding hair restoration techniques, procedures, and related issues, as well as encouraging and facilitating the free exchange of ideas, knowledge, and experience among physicians and assistants providing hair restoration. 